\title{
HEGEMONIA, CRISE ECONÔMICA E POLÍTICA: A DINÂMICA DOS CICLOS DO CAPITALISMO
}

\author{
HEGEMONY, ECONOMIC AND POLITICAL CRISIS: \\ THE DYNAMICS OF THE CYCLES OF CAPITALISM
}

Róber Iturriet Avila Doutor em Economia (Universidade Federal do Rio Grande do Sul/Brasil). Professor na Universidade Federal do Rio Grande do Sul (Porto Alegre/Brasil). E-mail: roberiturriet@yahoo.com.br.
Julice Salvagni

Pós-doutora em Ciências Humanas

(Universidade do Vale do Rio dos Sinos/Brasil).

Professora na Universidade Federal do Rio

Grande do Sul (Porto Alegre/Brasil).

E-mail: julice.salvagni@ufrgs.br. 


\section{RESUMO}

O objetivo desta revisão bibliográfica é analisar as dimensões hegemônicas em um contexto global de crise econômica e política à luz dos ciclos do capitalismo. Todas estas facetas do poder político, militar e econômico descortinariam os nexos do quadro atual, representativos à sociedade. Assim, desenvolvem-se pontos acerca da perspectiva econômica da crise em âmbito global, dando destaque à relação de mercado estabelecida entre os países emergentes e a soberania de potências econômicas. Pode-se perceber não apenas a mudança em relação às políticas macroeconômicas, mas também em relação ao papel que os países emergentes passam a ter na conjuntura mundial e as subsequentes crises políticas em alguns desses países.

Palavras-chave: Hegemonia. Crise econômica. Crise política. Ciclos do capitalismo. Macroeconomia.

\section{ABSTRACT}

The objective of this bibliographical review is to analyze the hegemonic dimensions in a global context of economic and political crisis in the light of the cycles of capitalism. All these facets of political, military and economic power would uncover the nexus of the current framework, representative of society. Thus, points are developed about the economic perspective of the crisis at a global level, highlighting the established market relationship between emerging countries and economic power sovereignty. One can see not only the change in relation to macroeconomic policies, but also in relation to the role emerging countries have in the global scenario.

Keywords: Hegemony. Economic crisis. Political crisis. Cycles of capitalism. Macroeconomics. 


\section{INTRODUÇÃO}

Este estudo tem por objetivo analisar as dimensões hegemônicas em um contexto global de crise econômica e política à luz dos ciclos do capitalismo por meio de uma revisão bibliográfica. Episódios recentes na cena internacional têm deixado patente determinadas incongruências do que ocorre com os Estados Unidos da América (EUA) e a sua ambição hegemônica. Embora esse país esteja reconhecidamente em uma situação de maior poder relativo ${ }^{1}$, ou seja, persiste com influência sobre o arranjo financeiro internacional e mantém peso político não desprezível, sinais de enfraquecimentos são avistados. O trabalho se propõe a investigar certos elementos que embasam e sinalizam perda de poder dos EUA, vislumbrar algumas consequências possíveis diante de tais dificuldades e associar com crises políticas subsequentes. Embora não esteja no escopo do trabalho observar as causas da crise vigente, convém desvelar algumas de suas implicações sobre a posição hegemônica dos EUA.

A presente discussão perpassa por inúmeros fatores que precisam ser analisados com alguma profundidade para desvendar a conjuntura recente, tais como a dominância tecnológica e científica, a supremacia militar e a capacidade de oferecer segurança, o domínio cultural e ideológico, a representatividade das empresas financeiras e não-financeiras (eficiência produtiva), a capacidade de impor sua vontade, a habilidade de legitimar a ordem corrente, a supremacia financeira, seja sob o ponto de vista da moeda internacional, seja pela credibilidade das contas do Estado. Todas estas facetas do poder político, militar e econômico descortinariam os nexos do quadro atual. Para ancorar essa análise, a segunda seção lançará luz acerca dos diferentes conceitos teóricos de hegemonia, perpassando pelas construções de Arrighi (1996), Wallerstein (2000) e Strange (1996).

Subsequentemente, desenvolver-se-á perspectivas econômicas da crise em âmbito global. As correntes teóricas são divergentes quanto à postura dos emergentes, indicando desde uma postura de certa passividade frente ao mercado estabelecido (EICHENGREEN, 2009), no que diz respeito à relação monetária e de fundo de reservas, até propositiva da gestão da conta capital (SPENCE, 2009) como forma de enfraquecer a influência do FMI. Assim sendo, a seção 3 traz o diálogo entre diversos autores contemporâneos sobre as interpretações da crise de 2008, paralelos com a crise dos anos 30 e possíveis desdobramentos futuros, em uma eventual nova regulamentação do sistema financeiro internacional.

Na seção 3, é explorada a interlocução entre as crises políticas e econômicas, amparando-se em aspectos levantados por Polanyi (2000), que aponta o desdobramento de crises econômicas em mudanças po-

\footnotetext{
${ }^{1}$ O termo "poder relativo" faz referência à posição de maior poder de um Estado frente aos demais e de sua capacidade de impor posturas. Ou seja, é utilizado, neste artigo, como sinônimo de "hegemonia". Sendo os elementos que embasam tal situação os mesmos que explicam a posição hegemônica.
} 
líticas e no arranjo financeiro internacional. Um ponto importante da presente apropriação leva a sublinhar a articulação dos BRICS na tentativa de ampliação do espaço político no momento posterior à crise de 2008 e com possíveis consequências à estabilidade norte americana. Essa dimensão permite a associação das crises econômicas e instabilidades financeiras com alterações políticas e significativas rupturas em âmbito global. Por fim, na última seção, estão registradas as considerações finais.

\section{CRISE DE HEGEMONIA: O PODER ESTADUNIDENSE}

No tempo em que se propõe a discutir a influência dos EUA perante as demais nações, há que pesar, ao menos brevemente, o que se considera por "hegemonia" ou "dominação", os quais representam este poder. De acordo com a visão de Arrighi (1996, p. 27), hegemonia se configura como a "capacidade de um Estado exercer funções de liderança e governo sobre um sistema de nações soberanas”. Nestes termos, é um poder que se explicita pela liderança intelectual e moral, seja ela retratada pela capacidade coercitiva (militar) ou pelo consentimento. No caso da coerção, trata-se de "dominação" apenas. Já o hegemon lidera o sistema de Estados, representando, ou ao menos procurando representar, o interesse geral.

Já Wallerstein (2000, p. 255) entende que hegemonia ocorre quando há um desequilíbrio de forças de tal forma que uma grande potência pode impor seus desejos em nível econômico, político, militar e cultural. Este poder advém da eficiência das empresas locais na produção agroindustrial, no comércio e no setor financeiro. Desta maneira, o autor pontua que a hegemonia se dá quando há dominância simultânea nas três esferas, referendado a preeminência de sua eficiência. Sob esta situação, as demais nações ficam submissas do ponto de vista político e ideológico.

A imposição ideológica se manifesta, geralmente, pela defesa do liberalismo tanto no comércio como no fluxo de capitais. Um contexto liberal permite ao país hegemônico a ampliação de seus mercados, de forma que suas firmas, que já obtiveram ganhos de escala advindos de sua acumulação de capital e tecnologia pregressas, possam exportar para os demais países ou até mesmo instalar filiais neles, remetendo seus lucros para a matriz. Assim sendo, há oposição às barreiras alfandegárias e às políticas que restringem o livre-comércio. No que tange à política, o país hegemônico costuma interferir nos processos internos dos outros Estados. Tal estratégia ocorre quando as circunstâncias destes países colidem com o poder, ou seja, a intervenção visa assegurar seus interesses e suas vantagens.

Há, ainda, a pujança militar. Wallerstein (2000) expõe que antes de serem efetivamente hegemonias, há relutância em desenvolver as forças militares. Entretanto, à medida que se observa a possibilidade de ocorrer enfraquecimento de forças impositivas no campo político e ideológico, torna-se indeclinável obter poder militar para enfrentar algum eventual rival. Situação esta que também objetiva intimidar os demais 
Estados e resulta na estabilidade de sua influência hegemônica. Dado que o autor considera que o período efetivamente hegemônico se dá quando há dominância produtiva nos três setores citados anteriormente, a perda desse poder começa, portanto, quando o setor agroindustrial deixa de ter a mais elevada eficiência produtiva. Diante desse cenário, o país busca resgatar sua liderança através da força política e militar, contudo, é possível manter estas supremacias sem persistir na posição hegemônica.

A organização da sociedade moderna é orientada pela vida material, fato que torna fundamental a análise do poder econômico e financeiro enquanto se pensa nos Estados e nas suas influências mútuas. Contudo, há que se destacar outros fatores que estão relacionados à hegemonia. Gramsci (apud GRUPPI, 1978) destaca que a sociedade é um todo orgânico que se explica pela base econômica, mas não é reduzido a este fator. As instituições da sociedade estão interconectadas com a subordinação cultural.

Ou seja, sob esta visão, conquistar a hegemonia engloba a noção de representatividade cultural de forma que um grupo se apresenta como aquele que atende aos interesses e valores de todos, de tal sorte que há consentimento na liderança exercida, envolvendo a todos no mesmo compromisso. Dado que o grupo hegemônico assume a reivindicação dos demais como sua, torna-se indispensável discutir os aspectos econômicos, haja vista que as expressões das vontades e dos interesses estão intimamente manifestadas às questões econômicas. Assim, a infraestrutura da vida material possui uma simbiose com a superestrutura ideológica, política, cultural e moral.

Strange (1996) entende que o structural power permite que o modo de produção e a base da política econômica global sejam definidos por quem detém tal poder. Este é oriundo do controle sobre a segurança (capacidade de oferecer proteção quando há conflito), da produção (combinação capital/trabalho e consolidação do sistema social), do crédito (possibilidade financeira de controlar o poder de compra) e do conhecimento (crenças/ideias). Desta forma, há interconexão entre o poder político - que necessita do poder "aquisitivo" - e o poder econômico - precisa da sanção política.

Sob estas bases tocantes à capacidade deliberativa e influência interestatal, cabe analisar o comportamento de algumas destas facetas para se investigar o processo que parece estar se firmando de perda de poder por parte dos EUA. Impõe-se certo refinamento sobre os requisitos mais preeminentes para se verificar como este corpo teórico se manifesta no quadro presente.

O aspecto econômico é vital no tempo em que se analisa o poder hegemônico no sistema capitalista. Cumpre observar que a sustentação econômico-financeira é pilar primordial ao país que deseja manter influência sobre os demais. Os EUA sofrem de carência de recursos e sua dependência financeira é cada vez mais expressiva. Há imposição de recorrência a outros Estados nacionais, os quais ganham mais poder frente ao seu devedor. Erro este cometido pela Grã-Bretanha em fins de seu processo hegemônico. Phillips (1993) entende que "a preocupação excessiva com as finanças econômicas e a tolerância para com as dívidas 
parecem ser típicas das grandes potências econômicas em seus estágios finais" (PHILLIPS, 1993, p. 194 apud ARRIGHI, 1996, p. 325). Gramsci (apud GRUPPI, 1978) salienta que um grupo hegemônico possui a capacidade de influenciar a vontade coletiva a assumir outros valores, crenças, práticas políticas e concepções de mundo diferentes das pregressas. Esta identificação cultural, que encontra nos intelectuais o seu papel central, visa impactar sobre o pensamento político e sobre a organização da sociedade para que a dominância hegemônica seja consentida e para que seus interesses não sejam conflitados. Este convencimento busca conquistar a maioria, abarcando toda a sociedade civil em direção aos interesses hegemônicos.

Estes elementos foram impulsionados pela conjuntura econômica na década de 1980 e 1990. Em face de um período de elevada inflação ao redor do mundo, aliada à estagnação, os países em desenvolvimento acabaram assumindo elevadas dívidas, de tal maneira que eles passaram a ter dificuldades de amortizar suas dívidas devido à escassez de divisas estrangeiras, agravada pelo desinteresse dos agentes financeiros em emprestar recursos.

Para solucionar tais problemas, foram implementadas as recomendações do Fundo Monetário Internacional (FMI), as quais visavam o equilíbrio externo. Nos períodos de constrangimento de divisas, tais países recebiam auxílio do FMI com condicionantes que objetivavam as condições favoráveis ao crescimento. Nestes termos, a chamada reforma estrutural se tornou ordem mundial. Dentre as políticas prescritas destas reformas são notáveis o controle da inflação, inibição do controle de capitais, privatizações, equilíbrio fiscal, desregulamentações, redução da intervenção estatal e aumento da concorrência bancária.

Tais medidas desencadeariam em maior eficiência e equilíbrio nas contas com o resto do mundo. Ao tempo que o FMI acentuava as vantagens de um mercado financeiro internacional livre, os Estados nacionais reduziram a ação na economia e deixavam a cargo do mercado as "políticas" de crescimento. Para tanto, os governos não economizariam em austeridade e nem nas políticas recessivas, uma vez que o desequilíbrio no balanço de pagamentos era diagnosticado como um excesso de demanda ocasionado pela expansão fiscal.

Convém descortinar, no entanto, quais interesses eram atendidos nesta submissão às políticas determinadas pelo FMI e que ideologia está por trás deste discurso. Carvalho (2000, p. 8) argumenta que este ambiente está sob o pano de fundo de uma maior participação do Tesouro Americano no FMI e seu consequente incremento de poder naquela instituição. Desta feita, a liberdade dos mercados financeiros internacionais ficou mais virtuosa sob a visão do FMI.

Para demonstrar os bons fundamentos da economia, os países removiam a regulamentação e aceitavam a liberalização, absorvendo sacrifícios em nome da disciplina. A ideologia da eficiência alocativa era transmitida pelo FMI sob forte influência americana (CARVALHO, 2000). Em assim procedendo, o fundo se intrometia nas decisões dos governos e restringia políticas autônomas, como pontua Carvalho (2000, p. 16, tradução própria): "Políticas de longo prazo, por outro lado, são concebidas para prevenir qualquer 
aventura intervencionista por parte dos governos nacionais que poderiam comprometer o 'sentimento dos investidores".

O alinhamento era, em última instância, ao poder americano. Tavares (1997) caracteriza este período como a retomada da hegemonia americana; já estes tiveram expressiva capacidade de impor o enquadramento econômico-financeiro e político-ideológico, sendo visualizado como única saída possível. Embora houvesse dominação, ela era consentida por estes países, situação esta definida pela autora como autêntica hegemonia. Esta conjuntura se estabelece, segundo a autora, devido à política deliberada pelos EUA com intuito hegemônico e não devido às próprias forças daquele mercado. O cenário da década de 1980 permitiu aos Estados Unidos ditar as novas regras, enquanto os demais países ficavam circunscritos aos ditames daquele.

Deste modo, não apenas houve a prescrição do caminho a ser seguido, como também ocorreu a influência sobre a vontade coletiva, haja vista que os políticos eleitos ao redor do mundo, particularmente na América Latina, estavam alinhados com esta estratégia liberal. A própria população acreditava que aquele era o rumo a ser tomado. Houve convergência em torno do projeto político liberal, movimento fortemente relacionado com as ambições dos EUA, tal como asserções de Wallerstein (2000).

Este processo foi apoiado por intelectuais. Cervo (2000) aponta que a maioria deles passou a defender as práticas de liberalização, de forma a eliminar o confronto com o centro, ou seja, aceitando a liderança americana e barganhando a partir desta. Os Estados se adaptaram a este paradigma, sujeitando a estrutura econômica interna aos padrões de inserção econômica internacional. Ou seja, houve apologia à subserviência do projeto concebido no centro capitalista. Neste sentido, ao propor uma abordagem alternativa à economia política institucionalista, Chang (2002) destaca que o problema central da estrutura neoliberal não reside em suas conclusões políticas excessivamente anti-interpretativas, ou seja, voltadas ao conceito de hegemonia, mas na maneira em que prevê o modus operandi do mercado, do Estado, das instituições e suas inter-relações.

Os percalços no transcurso da crise vigente alteraram este ambiente ideológico. Para equilibrar os recorrentes déficits externos, segundo os cânones clássicos, dever-se-ia implementar políticas fiscal e monetária restritivas. Adicionalmente, a recomendada redução do Estado na economia teria o papel de dissipar a ineficiência. No entanto, na crise, o governo americano se valeu de intensa intervenção para reduzir os impactos perversos de sua omissão.

As reformas propostas pelo FMI e pelo Banco Mundial foram ineficazes, já que ignoraram as diferenças institucionais entre os países, defendendo políticas idênticas para estruturas distintas (CHANG, 2007). 0 não-entendimento de que existe uma multiplicidade funcional das instituições pode levar ao institutional mono-tasking (CHANG, 2007). Trata-se da delegação às instituições ao cumprimento de uma única função, renegando o caráter multifuncional das instituições apontado pela Economia Política Institucionalista. Um 
erro por não explorar o inteiro potencial das instituições, por tornar mais fácil a captura de grupos de interesse pelas instituições e por negligenciar como ela se comporta em relação às demais funções que as instituições exercem (GRAZZIOTIN; HERRLEIN JÚNIOR; AVILA, 2015).

Contradições estas amplamente discutidas, as quais, por este motivo, dispensam maior aprofundamento. É oportuno, entretanto, frisar que este contexto aflorou políticas econômicas mais intervencionistas também em outros países, notadamente no Japão e na União Europeia, impostas pela própria força dos fatos, os quais já se realçam. Cabe notar que, como aponta Chang (2004), quase todos os países bem-sucedidos valeram-se de proteção à indústria nascente e de outras políticas ativistas quando eram economias em catching up. Nessa medida, a capacidade de influência ideológica dos EUA sobre os demais países parece reduzida após a crise de 2008.

De outro lado, é inconteste que os EUA possuem a mais poderosa força militar do mundo. Há, adicionalmente, uma distância crescente entre a potencialidade militar estadunidense e dos outros países de forma que sua capacidade é superior à soma das forças militares do resto do mundo, segundo Correia (2004). Os EUA estão também na fronteira tecnológica se destacando como o país que mais investe em pesquisa e que possui elevado nível de escolaridade da população.

Mesmo assim, as posições unilaterais na área militar ocasionaram certo desconforto na cena internacional. Ao mesmo tempo, os EUA passam a depender mais dos outros países para financiar suas contas. Dentre os diversos autores que apontam a emergência de jogadores com mais força, Roubini (2008) destaca a ascensão: a) do Brasil - como líder regional e com maior peso global; b) da Rússia - com espaço militar na região e capacidade financeira; c) da China - com investimentos na África e na América Latina e com expressiva capacidade econômica; além de d) Índia e e) África do Sul. Tais países, aliados aos árabes, representam grande parte dos credores americanos e deixam os EUA mais vulneráveis, mesmo que, por ora, seja de interesse destes a recuperação americana. Ainda assim, erros geopolíticos e financeiros deixam os EUA mais expostos a fragilidades. Torna-se visível o aumento de jogadores na cena internacional, permitindo maior capacidade de negociação a estes e maior autonomia de políticas, tais como as observadas na América do Sul.

\section{A CRISE ECONÔMICA DE 2007-2008 E O PÓS-CRISE: UMA REVISÃO DA LITERATURA}

Tendo por base a influência geopolítica dos países emergentes, enfatiza-se que a crise econômica de 2007-2008 gerou impactos a ponto de nenhuma regulação nacional ser capaz de evitar a instabilidade financeira dos mercados globais (EICHENGREEN, 2009). Em não havendo esta regulamentação, a globalização financeira tende a retroceder em alguma medida, a começar por restrições a operações externas, com impacto secundário no crescimento mais lento do crédito, assim como na menor diversidade de produtos financeiros. 
Ao questionar se a ênfase nas exportações não teria ido longe demais a alguns países emergentes, Eichengreen (2009) indica que a crise foi capaz de mostrar os riscos da dependência excessiva do mercado financeiro externo. Os países emergentes que estavam com déficit em conta corrente enfrentaram sérias dificuldades, particularmente na Europa oriental. O caso da Grécia é icônico, uma vez que a entrada do país no Zona do Euro fez ampliar seus déficits externos, os quais eram financiados pelo fluxo de capitais. Após a crise de 2007-2008, os capitais, com plena mobilidade, deixaram o país, impondo uma crise sem precedentes para um país desenvolvido (DE BEM, JUBRAN, 2016).

Eichengreen (2009) pontua que os emergentes sempre foram insatisfeitos com o arranjo financeiro internacional, particularmente porque, em última instância, dependem dos EUA. Este incômodo tem sido explicitado com mais vigor no mundo pós-crise, sobretudo pelos BRICS, especialmente no que se refere ao dólar como moeda internacional e à formatação do FMI.

No que diz respeito aos impactos da recente crise, Eichengreen et al. (2009) traçam um paralelo da economia global entre as crises de 1929 e 2008, estudando seus efeitos reais sobre a economia. Os dados do trabalho apontaram que a manufatura, os mercados acionários e o comércio internacional caíram tanto quanto ou mais na recente crise do que há 80 anos, em termos globais. Havia, pois, um ceticismo na crise de 1929 em relação aos estímulos fiscais e monetários, especialmente em um ambiente marcado por falências, taxas de juros próximas de zero e superendividamento.

Conforme Eichengreen et al. (2009), verificou-se que, de uma forma geral, as políticas monetária e fiscal foram mais rápidas e mais fortes agora do que em 1929-1930. Os resultados deste estudo sugerem que em 1930 a política fiscal fez pouca diferença nos anos seguintes porque não ocorreu na escala necessária, e não por que era ineficaz. Também há indícios de que a Política Monetária foi eficaz: a taxa de juros definida pelos bancos centrais foi efetiva no incremento do PIB per capita. Ambos os indícios sinalizam que os estímulos fiscais e monetários são benéficos no combate à queda da demanda agregada e ao risco de deflação.

Para Spence (2009), as recomendações aos emergentes foram mudando de acordo com o tempo e com as crises. Antes de 1997, a ordem era imitar os ricos com pouca regulação. Após 1998, o aconselhamento era para que se buscasse a maturidade do sistema financeiro e o acúmulo de reservas. Em 2007-2008, sendo a crise originária do centro, ela deixa questões sobre a habilidade dos países em lidar com os riscos. Isso faz aumentar a rejeição à autorregulação dos mercados, nublando o futuro da economia global. Assim, os países emergentes tendem a rever suas políticas de abertura da conta capital, tendo especial atenção à fuga de capitais, que reduz crédito e interfere no câmbio. Nesta premissa, oposta à de Eichengreen, o acúmulo de reservas ganhará mais força, assim como a gestão da conta capital, fazendo com que o FMI passe a ser percebido como pouco eficaz para estabilizar os capitais voláteis. 
Sob outro aspecto, Krugman (2009) alerta que a crise de 2007-2008 não pertence a apenas um único modelo, já que não é apenas uma crise bancária ou cambial, tampouco deu-se pela falta de liquidez ou crise de inadimplência. Neste sentido, trata-se de uma crise política e econômica, que reflete apenas uma parcela pequena acerca dos efeitos do capitalismo.

No que tange às estratégias de crescimento, Spence (2009) aposta que elas não serão abandonadas e que os emergentes manterão o discurso pela abertura comercial, embora o crescimento tenda a ser menor. Ademais, os pacotes anticíclicos tendem a reduzir a poupança dos emergentes e o controle sobre os ativos financeiros se intensificará. O autor complemente que o governo passará a ser mais importante tanto no controle como e na regulação doméstica do setor financeiro, com destaque aos bancos nacionais, preteridos por esses trabalharem junto com os governos nas respostas às crises. Ou seja, os emergentes manterão política de crescimento em tempos de crise, focando, adicionalmente, na estabilidade e na regulação, para reduzir a instabilidade.

O processo de integração tanto financeira como comercial tem sido o procedimento básico de desenvolvimento há séculos e acentuada nos últimos 30 anos, acelerando a integração entre as nações e trazendo benefícios em termos de qualidade de vida para a maioria da população. No entanto, como afirmam Caballero et al. (2006), ainda que uma maior integração comercial e financeira possa acelerar o crescimento econômico, ela também pode agravar os efeitos negativos de choques externos. Assim, e diante da crise financeira global que ocorreu em 2008 e suas consequências reais sobre as economias, a análise das diversas perspectivas de políticas macroeconômicas torna-se não apenas conveniente, mas necessária para orientar ações que visem a reduzir vulnerabilidades, seja prevenindo-as ou remediando-as.

Piketty (2014) observa que mudanças políticas corrigiram distorções no século XX e permitiram meIhorias econômicas e sociais. De toda sorte, as mudanças ocorridas no século XX não ocorreram por boa vontade e sim porque havia um contexto de crise, de guerra e da ameaça comunista estabelecida pela ordem internacional. Nas décadas de 30 a 70 os movimentos de esquerda cresceram pelo mundo, o que se tornou uma ameaça. No final da década de 70, os países com ideias socialistas estavam perdendo poder. Diante de uma nova crise econômica ocorrida na década de 70, houve mudança na política e na economia. Assim, a mudança política só ocorre quando o capital é obrigado a ceder. Uma configuração mais regulada e com viés social exige profundas alterações políticas e econômicas que não são de fácil consecução. A mobilidade de capitais, por exemplo, que está dentro do liberalismo que o Piketty (2014) compactua, é uma patente maneira de doutrinar os governos de acordo com os interesses do capital, além dessa aumentar o poder de influência política do capital, sobretudo no caso dos países emergentes, com maior vulnerabilidade financeira. Caso o país não se enquadre na política econômica, há fuga de capitais, desvalorização cambial, elevação da inflação, escassez de crédito e possivelmente redução do investimento, que levará a uma crise e ao desemprego. 
A vulnerabilidade dos países emergentes é destacada por Caballero et al. (2006) que admitem a existência de uma relação entre termos de troca e choques de taxas de juros com a volatilidade macroeconômica. Eles sugerem que mecanismos financeiros podem ter efeitos multiplicadores: redução do patrimônio líquido dos países, forte contração de crédito com retirada de recursos por parte de investidores, dolarização extensiva de dívida, ausência da figura do emprestador de última instância, que pode gerar uma insegurança nos agentes econômicos, e maturidade da dívida externa.

Já Kregel (2008) observa a existência de desequilíbrios financeiros internacionais crescentes. Ele defende que esses desequilíbrios são historicamente resultado do processo de catching-up dos países em desenvolvimento tardiamente industrializados. A inexistência de um sistema monetário internacional fez com que os ajustes dos desequilíbrios fossem feitos através de crises financeiras, já que não existe uma instituição capaz de fornecer a liquidez requerida para a expansão do crescimento. Assim, os países emergentes foram crescentemente sendo levados a acumular reserva através de seus superávits na conta corrente, com o intuito de se proteger da reversão dos fluxos financeiros, mas também para financiarem o consumo de suas exportações, o crescimento interno e o aumento de emprego. Isto é, houve uma mudança de fluxos financeiros em que os países emergentes saíram de sua posição de devedores para credores, com a Ásia sendo o ator principal e em menor escala, a América Latina.

Esta mudança, segundo Toloui (2007), se deu tanto por razões microeconômicas (aumento de poupança e redução de investimentos não produtivos) como macroeconômicas (redução da volatilidade do capital). Como resultado, Toloui (2007) enxerga uma correlação entre a qualidade da dívida pública e o superávit/déficit da conta corrente dos países, em que uma situação de superávit na conta corrente tende a reduzir taxas de juros e desenvolver o mercado de dívidas de moedas locais. Além disso, ele percebe uma tendência de redução de taxa de juros, melhoria institucional e superávit em conta corrente de alguns países, que podem estar levando a uma convergência internacional dos juros.

O estudo da UNCTAD (2007) também aponta para essa mudança de fluxos de capital como resposta às crises da década de 1990, adicionando a política de intervenção cambial ao pacote de ações. Essas políticas tendem a evitar, ou limitar desvios da taxa de câmbio e promover segurança para os ciclos do mercado financeiro internacional. Entretanto, o estudo defende que uma abordagem cooperativa de parceiros regionais pode dar melhores resultados que ações nacionais separadas.

Sobre as políticas de prevenção e estabilização da volatilidade macroeconômica, Caballero et al. (2006) enfatizam ações de reservas internacionais em nível de custeio das dívidas de curto prazo (com o custo de postergação do consumo) e controle de capitais (com custo de possível redução de entrada de capital). Além disso, o sucesso de políticas passa pela flexibilidade cambial, regime de metas de inflação, credibilidade e por um mercado financeiro líquido e desenvolvido, que destaque a credibilidade e transparência. 
Ostry et al. (2010) destacam que a adoção dos controles de capital é realizada com os objetivos de reduzir o volume de entradas e limitar a apreciação da taxa de câmbio, alterando a composição dos vencimentos das entradas para diminuir a fragilidade financeira e prover independência adicional de política monetária. A evidência empírica mostra claramente que os controles são eficazes em mudar a composição das entradas, permitindo acesso a passivos com maior maturidade. Assim, os controles são úteis para reduzir a fragilidade financeira, permitindo, passar pela crise de forma menos custosa.

Contudo, na decisão de recorrer a controles de capital, é importante levar em conta não apenas efeitos nos países individuais, mas os efeitos multilaterais, para o sistema econômico como um todo. Com relação a isso, Ostry et al. (2010) argumentam que a recuperação global da economia é dependente de políticas macroeconômicas de ajuste nos países emergentes e as formas de controles generalizada poderia exacerbar desequilíbrios globais e atrasar outras reformas necessárias. Neste sentido, o fato de um país adotar controle pode induzir outros, resfriando a integração financeira e a globalização, gerando perdas no produto e no bem-estar. Assim, dimensões multilaterais também devem ser levadas em conta na avaliação da adoção de controles de capital.

Blanchard et al. (2010) tentam encontrar o novo contorno da política macroeconômica após a crise de 2008. Segundo os autores, antes da crise, havia uma única meta a ser buscada e apenas um instrumento de política: desde que a inflação estivesse estável, a política monetária teria feito seu trabalho. A política fiscal era tida como papel secundário e ineficiente, e a regulação financeira não era pensada dentro do cenário de política macroeconômica.

A meta primária dos bancos centrais, se não a exclusiva, era a manutenção da inflação em um nível estável e baixo, para não causar distúrbios no produto. Essa era a política ótima mesmo quando a economia era afetada por choques. Havia um consenso de que a inflação não deveria ser só estável, mas muito baixa. Blanchard et al. (2010) afirmam que a política monetária focou-se crescentemente no uso de um único instrumento, a taxa de juros. Isso se deu pela assunção de duas hipóteses: que os efeitos reais da política monetária se dão através da taxa de juros e dos preços dos ativos e que, adicionalmente, estas variáveis estavam relacionadas através de arbitragem. Tendo em vista esse cenário, a intermediação financeira era negligenciada e a regulação e supervisão focavam-se em instituições e mercados individuais, ignorando-se as suas implicações macroeconômicas.

Blanchard et al. (2010) destacam algumas lições da crise, dada a conjuntura anterior: inflação estável pode ser necessária, mas não é suficiente; inflação baixa limita o escopo de política monetária em recessões deflacionárias; política fiscal é uma ferramenta contracíclica importante; e regulação não é macroeconomicamente neutra. Contudo, mais do que apontar as falhas de políticas existentes, os autores indicam um novo quadro de políticas. Segundo eles, agora, após a crise, sabe-se que a política macroeconômica deve ter muitas 
metas, mas que também conta com inúmeros instrumentos, tais como a política monetária, a política fiscal e a regulação. O desafio é aprender como usar esses instrumentos da melhor forma. Dentre eles, destacam-se a combinação de política monetária e regulação e o desenho de melhores estabilizadores automáticos. Assim, reforça-se a necessidade ter de baixa dívida pública para ter um maior espaço de política fiscal quando necessário e uma boa regulação, assim como dados transparentes nas áreas monetárias, financeiras e fiscais.

Irving Fisher escreve o seu artigo de 1933 no intuito de apresentar sua percepção da teoria do ciclo, particularmente com base na Grande Depressão. Em sua visão, duas variáveis chaves explicam a crise: o endividamento elevado e a deflação (ou variação de preços). Outros fatores explicativos são, para ele, adjacentes, como, por exemplo, o investimento excessivo, oriundo do elevado endividamento. Ainda assim, existem sete variáveis secundárias com relevante poder explicativo, quais sejam, meios de pagamento, velocidade dos meios de pagamento, lucros, valores líquidos, taxa de juros, confiança nos negócios e comércio. Ao explicar logicamente o desencadear e a conexão destas variáveis, Fisher conclui que, com exceção do endividamento, todas as demais se originam da queda nos preços. Neste sentido, o dinheiro fácil e as oportunidades de investimento, aliadas ao excessivo otimismo da década de 1920 levaram a uma bolha de crédito e a um endividamento irresponsável.

Em termos teóricos, Fisher pontua que caso ocorresse apenas o endividamento sem uma redução de preços, o ciclo não seria tão grave. Ao mesmo tempo, a ocorrência de deflação não pelo endividamento teria efeito menor. Ou seja, um ciclo mais devastador ocorre quando ambos elementos estão juntos e de maneira conectada. Sendo que a ocorrência de um evento agrava o outro. Nesta linha de pensamento, entretanto, não há uma explicação para grandes perturbações como a de 1930. Para ele, estes casos não se justificam na superprodução ou no descompasso entre investimento e poupança, senão nas duas variáveis chaves supracitadas. Diante deste contexto, é possível evitar uma crise daquela proporção através do aumento de preços ao nível em que os débitos foram contraídos. Assim, o autor entende que intervenção do governo Roosevelt e o controle dos preços foram medidas acertadas.

Sob um pensamento semelhante ao de Fisher, Milton Friedman e Anna Schwartz (apud BERNANKE, 1983) entendem que a crise bancária desencadeou seu efeito real na economia tão-somente pela redução da quantidade de moeda em circulação. Ben Bernanke (1983), ao contrário, acha que esta variável sozinha não explica a profundidade e a duração da crise, pois existem outras variáveis que não são monetárias. Este é o argumento central de seu artigo e a sua contribuição para a literatura.

Como Fisher, Bernanke (1983) identifica o problema do endividamento elevado dos anos 1920 e a gravidade deste problema em face da deflação dos anos 1930, o que levou à insolvência dos devedores. Um aspecto salientado por Bernanke e que é visto marginalmente em Fisher é o impacto da queda da confiança nas instituições financeiras e quão destrutivas são as corridas aos bancos, sobretudo no período da década 
de 1930, pois naquele tempo a maioria dos bancos era de pequeno porte. O receio de "corridas aos bancos" impingiu um conservadorismo aos agentes financeiros capaz de agravar a crise para além da redução da oferta de moeda. Os bancos preferiam manter posições mais líquidas e mais seguras, forçando uma contração creditícia. Isso porque existe assimetria de informação no mercado de crédito e, portanto, é custoso saber se o devedor é um bom pagador ou não.

Esta visão da perda da confiança pelos agentes econômicos pode ser aproximada à perspectiva de John Maynard Keynes, autor que, como se sabe, explora como os receios e as incertezas dos homens, em face das oscilações das relações econômicas, impactam na atividade econômica como um todo.

Para sustentar sua argumentação, Bernanke (1983) desenvolve uma análise sobre os custos da intermediação financeira. Ao longo da crise dos anos 1930, a desvalorização das garantias de crédito, a ineficiência no processo de alocação de crédito, a busca por ativos mais líquidos e a própria inadimplência ocorrida na crise desencadeiam em maior custo do crédito. A redução do crédito e a falta de confiança diminuíram a capacidade produtiva. Bernanke expõe que mesmo as empresas com disponibilidade de recursos não aumentaram a produção devido à expectativa de redução da demanda, ou seja, devido a motivos não monetários. O autor apresenta, ainda, seu modelo regressivo que sinaliza que a crise fez o crédito reduzir também por efeitos psicológicos. A demora para reestabelecer canais de crédito e para solucionar o problema da insolvência dos devedores auxiliam a justificar a propagação da Grande Depressão, assim como a manutenção dos efeitos não monetários.

Bernanke (1983) parece entender que a intervenção dos governos para estabelecer a confiança se justifica apenas em momentos de crise. Neste sentido, pode ser entendido como certo afastamento das ideias keynesianas, as quais veem a incerteza das relações econômicas como algo constante, mesmo que não generalizado. Contudo, o formato adquirido pela crise financeira de 2007/2008 vai além de um simples descompasso entre oferta e demanda agregada, no que muitos tentariam fazer uma alusão precária às semelhanças quanto à Grande Depressão dos anos 30. Tal formato tem origens no que Minsky (1986) convencionou como "money manager phase of capitalism", ou seja, a capacidade de criação e de manipulação da riqueza nacional, sem necessariamente passar pela esfera produtiva, na também chamada "shadow banking system", a sombra do sistema bancário.

No contexto da América Latina e Caribe, uma das variáveis mais afetadas pela crise foi o comércio internacional. Diante disso, pode-se afirmar que, a fim de estimular a cooperação regional entre os países da América Latina e Caribe, um dos aspectos mais relevantes diz respeito ao fomento do comércio intrarregional por meio de financiamentos, desburocratização e maior agilidade dos processos, maiores informações sobre oportunidades comerciais na região, além da criação e manutenção de uma infraestrutura adequada para apoio às negociações internacionais (ROSALES, 2010). 
No contexto global, conforme a visão de Gross (2009), as maiores probabilidades indicam as seguintes conclusões estratégicas para o cenário dos próximos anos: (I) as taxas de juros globais se manterão baixas durante períodos prolongados; (II) os estímulos fiscais e financeiros serão ponto chave para a retomada dos investimentos; (III) os investidores deverão continuar a antecipar e associar-se às políticas dos governos; (IV) as economias asiáticas e relacionadas (Brasil e Austrália) dominarão o crescimento global futuro; e (V) o dólar é vulnerável a longo prazo. Neste sentido, Gross (2009) acrescenta que a economia global passará por um período de transformação DDR (desalavancagem, desglobalização, re-regulamentação), onde salienta alguns aspectos de mudança: fim do capitalismo ao estilo dos Estados Unidos; crescimento do setor privado versus crescimento impulsionado pelo setor público; e mudança na liderança econômica global: cada vez mais, a China dá mostras de que em breve será o centro da economia mundial.

O que tanto Wray (2010) e Kregel (2010) vêm a alertar em relação às possíveis soluções para o enfrentamento do pós-crise, tem a ver com o fato de que as ações de política econômica do governo norte-americano se restringiram ao socorro do sistema via política fiscal, mas que as bases que geraram toda a alavancagem desenfreada não foram removidas. Os ditos fundamentos do sistema não passaram por reestruturações institucionais, já que a regulação e a supervisão bancária não conseguiram, até o momento, estabelecer e cobrar com precisão os papéis a serem desempenhados pelos bancos comerciais e pelos bancos de investimento. Por esse motivo, há proposições de uma nova regulamentação que cumpra o mesmo papel exercido pela legislação do New Deal, da década de 30. Neste sentido, a atual competição interbancária é resultado justamente da remoção dos impedimentos legais que vigoravam sob a "Glass-Steagal New Deal Legislation", cuja maior ênfase se dava na proibição da inovação de produtos bancários para os correntistas a partir da mobilização de "operações de longo prazo de mercados de capitais".

\section{CRISES POLÍTICAS E A GRANDE TRANSFORMAÇÃO}

Polanyi (2000), em A grande Transformação, destaca a relação das crises econômicas com a dimensão protetiva dos Estados, portanto, em seu sentido político. Essa premissa sugere um entendimento das crises do capitalismo como sendo revestidas de múltiplas facetas que vão além de uma perspectiva econômica, já que dialogam com a esfera política e comunitária. Neste sentido, as Crises de 1930, 1970 e 2008 trouxeram mudanças políticas e no arranjo financeiro internacional, que podem acarretar em significativos espaços de instabilidade política.

Faz-se mister destacar que, na concepção do autor, o poder econômico baliza as relações políticas entre os países. Como consequência, a estabilidade (ou a falta dela) nas relações econômicas enseja períodos de paz (e de guerra). 
No século XIX, lastreado a égide liberal, o mercado autorregulado impunha três variáveis mutuamente conectadas: o equilíbrio de poder geopolítico, o Estado liberal e o padrão-ouro. O padrão-ouro expandia a autorregulação do mercado, o equilíbrio de poder se funda no padrão-ouro e o Estado liberal coroa este arranjo.

No que toca o equilíbrio de poder, o autor expõe que os cem anos de paz (1815-1914) se justificam pela defesa pragmática desta harmonia. Leia-se: mesmo que neste período tenham ocorrido conflitos, eles não foram generalizados entre as Grandes Potências. Isso porque a haute finance fazia o elo entre a política e a economia, estabilizando as animosidades. No início do século XX, entretanto, dois eixos de países se formavam, um grupo liderado pela Grã-Bretanha e outro pela Alemanha, inibindo o equilíbrio de poder e restringindo a capacidade da haute finance contornar conflitos. Assim, o colapso do padrão-ouro adquire, para Polanyi (2000), um papel emblemático do fim da harmonia política. Estando, ainda, conectado à crise da economia de mercado e à transformação mundial no pós-1930.

Para existir paz, era necessário ter equilíbrio de poder e restaurar o sistema monetário internacional, uma vez que este último garantiria a estabilidade cambial, viabilizando os negócios (pacifistas fortuitos). Haveria, neste caso, uma forte relação de equilíbrio de poder-paz, paz-comércio, comércio-padrão-ouro, padrão-ouro-mercado autorregulável. Inversamente, o fracasso no restabelecimento do padrão-ouro, em meio à fragilidade hegemônica da Grã-Bretanha, desencadearia no fim da harmonia política, no colapso do sistema econômico mundial, na falência da economia de mercado, no fim do Estado liberal e, para Polanyi (2000), na transformação de toda a civilização. Esta segunda alternativa marca a mudança do século XX acentuada pelo autor. Disputas hegemônicas e a Grande Depressão desaguam nas crises políticas, na Segunda Guerra Mundial e no crescimento do fascismo e do comunismo. Ou seja, a crise de hegemonia da Grã-Bretanha e a instabilidade política do Período Entreguerras destruíram as instituições do século XIX. A origem do processo, para o autor, está na tentativa de estabelecer o mercado autorregulável, o que desencadeou no seu colapso. Ou seja, os motivos são econômicos, mas com desdobramentos políticos relevantes.

Na década de 1970, em uma dimensão menor, uma nova crise econômica gera alterações políticas. A incapacidade do governo americano em sustentar o padrão monetário internacional dá a base para o colapso do Bretton Woods. Arrighi (1996) analisa esta crise nos anos 1970 sob três aspectos: militar, ideológico e financeiro. Respectivamente, devido às dificuldades no Vietnã, devido à falta de legitimidade do anticomunismo e devido à alteração do padrão monetário. Paralelamente, no ambiente do final da década de 1970, vislumbrava-se a Alemanha e o Japão como centros poderosos capazes de encaminhar uma multipolarização.

O ensaio de multipolarização não se verificou devido à vitória ideológica americana. Houve um realinhamento, em última instância, ao poder americano. Tavares (1997) caracteriza este período como a retoma- 
da da hegemonia americana, já que o país teve expressiva capacidade de impor o enquadramento econômico-financeiro e político-ideológico, sendo, ainda, visualizado como única saída possível. O cenário da década de 1980 permitiu aos Estados Unidos ditar as novas regras, enquanto os demais países ficavam circunscritos aos ditames daquele. Embora houvesse dominação, ela era consentida por estes países.

A toda sorte, o período subsequente marcou novas rupturas políticas, sobretudo na organização dos Estados Nacionais, com a fragilização do Estado de Bem-Estar Social, a emergência do neoliberalismo, uma nova fase de expansão financeira e desregulamentação dos capitais, a partir, principalmente, de políticas de reformas estruturais sugeridas pelo FMI, conforme apontado na seção 2.

Já no período recente, a crise de 2008 abriu espaço para outros países questionarem o arranjo do sistema financeiro internacional. Um exemplo de transformações globais em resposta ao descompasso econômico pode ser interpretado pela mobilização dos blocos. Como efeito do pós-crise de 2008, percebe-se a articulação do BRICS (Brasil, Rússia, Índia, China e África do Sul) buscando mais espaço político, conforme destacado na seção 3. Esses países chegaram a questionar o dólar como moeda internacional, requisitaram maior influência no FMI, na Organização Mundial do Comércio e no Banco Mundial. Em 2014, fundaram em Xangai o Novo Banco de Desenvolvimento ou "Banco do BRICS", como uma alternativa ao FMI e ao Banco Mundial nas necessidades de financiamento dos países em desenvolvimento, particularmente em oposição às políticas de restrição fiscal impostas pelo FMI. Esse movimento pode ser interpretado como uma contraposição ao poder hegemônico dos EUA.

Entretanto, após 2014, crises políticas se sucederam no BRICS e/ou em seus aliados. Destacam-se, por exemplo, a Ucrânia, a Síria, a Coreia do Norte, o Brasil e a Venezuela. No caso do Brasil, especificamente, após o processo de impeachment da presidente Dilma Rousseff, houve um claro realinhamento do governo que a sucedeu com os EUA. O governo ucraniano de Viktor Yanukovytch, que era aliado da Rússia, também foi deposto. No tempo da confecção deste artigo, há uma eminente derrubada do governo venezuelano de Nicolás Maduro, opositor dos EUA, sob a ameaça de intervenção militar dos EUA. Tal qual ocorre na aliada da China, a Coreia do Norte. Intervenção já ocorrida na Síria, aliada da Rússia, a qual não chegou a depor o governo. Não é descabido aventar que tais eventos tenham relação direta ou indireta do Departamento de Estado dos EUA, em linha com o que preconiza Wallerstein (2000): a possibilidade de interferência do país hegemônico sobre os processos internos dos Estados Nacionais que colidam com o poder, de forma a assegurar os interesses do hegemon.

A leitura de um cenário similar já foi antedita pelo Polanyi (2000), ao ponderar que uma sociedade subordinada e constitutiva aos poderes dos mercados produz um efeito destrutivo que, se associado às reivindicações em favor de proteção social, podem conduzir a crises políticas, guerras e polarização das sociedades. Dentre esta descrição do que Polanyi entende como sendo a grande transformação, contudo, há 
lacunas que negligenciam as formas de injustiça que não repousam sobre o mercado (FRASER, 2011). Essas instâncias de dominação social são centrais para propostas que busquem o desdobramento dos efeitos sociais gerados no pós-crise.

\section{CONSIDERAÇÕES FINAIS}

A despeito de seu enfraquecimento econômico-financeiro e da menor capacidade de impor suas prescrições, a supremacia militar americana é indiscutível. Existem, portanto, contradições nestes aspectos: há sinais de força e de fraqueza que sugerem uma possibilidade de futura quebra da hegemonia norte americana, todavia não concretizada. Mesmo que Wallerstein (2000) afirme ser possível uma supremacia sem a hegemonia, não se pode afirmar que os EUA deixaram esta posição. Ainda assim, é possível constatar episódios em que o consenso não foi atingido, ou seja, não havia consentimento sobre a dominação, como na invasão do Iraque e a forte resistência de representativas economias europeias. Adicionalmente, posturas não coerentes com a visão dos EUA ganham força, especialmente na América Latina.

No campo econômico e financeiro, é evidente a fragilidade atual visível através de sua conta corrente com trajetória insustentável. Sem esquecer do elevado endividamento do Estado americano, da perda de representatividade de suas empresas e também da abundância de dólares que expõem esta moeda à depreciação. Todavia, conforme Tavares (1997), houve, no passado, situações de constrangimento, os quais foram superados diante de mudanças em políticas monetárias e de revigoramento na força geopolítica dos EUA. Nesta linha, os citados pacotes têm espaço para revitalizar a economia americana, assim como a confiança em sua moeda, mesmo que o endividamento seja elevado.

Se por um lado Wallerstein (2000) considera que a dominância agroindustrial tenha sido perdida, de modo que a eficiência produtiva seja menos competitiva, e, adicionalmente, Arrighi (1996) desenvolva seus estudos para postular que há um declínio do poderio americano, cujo início teria ocorrido nos anos 1970 com a crise sinalizadora; por outro lado, deve ser reconhecido que existe uma força militar e política não rivalizada no presente momento. De toda a sorte, pode ser afirmado também que houve alguma perda de poder diante de todo este contexto.

A reação unilateral e belicista, o aumento do antiamericanismo pelo mundo, a dependência econômica vista nos sucessivos déficits fiscais e comerciais e, por fim, a deflagração da crise que iniciou em 2007 e que se agravou em 2008 permitem que quaisquer sugestões sobre o nascimento de uma nova estrutura geopolítica mundial ao menos sejam merecedoras de algum crédito. Entretanto, apesar de diversos indícios, não é possível prever com exatidão o momento em que os EUA deixarão de ser o principal país e passarão a mais um jogador na cena internacional, e nem se isso efetivamente ocorrerá. Sua força militar e tecnológica nos 
indica que, ao menos no médio prazo, não há espaço para uma nova superpotência mundial. Não é difícil, contudo, vislumbrar um futuro multipolar, tendo os EUA como a maior economia, convivendo com grupos fortes, existindo, ainda, dependência mútua.

Pode-se perceber não apenas a mudança em relação às políticas macroeconômicas, mas também em relação ao papel que os países emergentes passam a ter na conjuntura mundial. O caráter credor do mundo emergente, ligado a uma situação de crise financeira que se deu nos países centrais, incutiu dúvidas quanto às políticas que devem ser priorizadas, levando os agentes econômicos a olharem com mais atenção para a periferia e para as políticas ditas heterodoxas na ciência econômica. A possibilidade de se valer de controle de capitais e de acordos regionais mostra-se cada vez mais aceita enquanto políticas macroeconômicas legitimadas. Já a política fiscal, antes relegada ao papel secundário, passa a não ser mais rejeitada e transfigura-se, sendo aceita com alguns limites e imposições.

\section{REFERÊNCIAS}

ARRIGHI, G. Adam Smith in Beijing. Lineages of the Twenty-First Century. New York: Verso, 2007.

ARRIGHI, G. O longo século XX. Dinheiro, poder e as origens de nosso tempo. Rio de Janeiro: UNESP, 1996.

BERNANKE, B. Nonmonetary effects of the financial crisis in the propagation of the Great Depression. American Economic Review, v. 73, n. 3, p. 257-276, 1983.

BLANCHARD, O. J.; DELL'ARICCIA, G.; MAURO, P. Rethinking Macroeconomic Policy. Staff Position Note No. 2010/03. Washington, DC: International Monetary Fund, 2010.

BUREAU OF ECONOMIC ANALYSIS. U.S. International Economic Accounts. Disponível em: <http://www. bea.gov/>. Acesso em: 9 jun. 2009.

CABALLERO, R. J., CALDERÓN, C., CÉSPEDES, L. F. External Vulnerability and Preventive Policies, Serie de Libros Banco Central, X. Santiago de Chile: Banco Central de Chile, 2006.

CAETANO, J. R; LAHÓZ, A. A China vai conquistar o mundo e sua empresa está na mira. Revista Exame, São Paulo, n. 9, p. 20-35, abr. 2005.

CARVALHO, F. J. C. The Changing Role and Strategies of the IMF and the Perspectives for the Emerging Countries. Revista de Economia Política, São Paulo, v. 20, n. 1, p. 3-17, jan./mar. 2000. 
CERVO, A. Sob o signo neoliberal: as relações internacionais da América Latina. Revista Brasileira de Política Internacional, Brasília, n. 2, p. 5-27, 2000.

CHANG, Ha-Joon. Breaking the mould: an institutionalist political economy alternative to the neo-liberal theory of the market and the state. Cambridge Journal of Economics, v. 26, n. 5, p. 539-559, 2002.

CHANG, Ha-Joon. Chutando a escada: a estratégia do desenvolvimento em perspectiva histórica. São Paulo: Unesp, 2004.

CHANG, Ha-Joon. Institutions and economic development: theory, policy and history. Journal of Institutional Economics, 7, n. 4, p. 473-498, 2011.

CHANG, Ha-Joon. Rompendo o modelo: Uma economia política institucionalista alternativa à teoria neoliberal do mercado e do Estado. In: ARBIX, Glauco et al. (Org.) Brasil, México, África do Sul, Índia e China: diálogo entre os que chegaram depois. São Paulo: UNESP, EDUSP, 2002b.

CHANG, Ha-Joon. The economic theory of the developmental state. In: WOO-CUMINGS, Meredith. The developmental state. Itaca, New York: Cornell University Press, 1999.

CHANG, Ha-Joon; EVANS, Peter. The role of institutions in economic change. Paper for the meeting of the "Other Canon" group. Oslo, ago. 2000.

CHANG, Ha-Joon. Understanding the relationship between institutions and economic development: some key theoretical issues. In: CHANG, Ha-Joon (Org.). Intitutional Change and Economic Development. United Nations University Press, 2007.

CORREIA, P. “Império mundial e acções preventivas”. In: Civilização Ou Barbárie, 2004, Serpa. Disponível em: <http://resistir.info/serpa/anuncio.html>. Acesso em: 19 jun. 2009.

DE BEM, A. P; JUBRAN, M. A ampliação das assimetrias na Zona do Euro como fator da crise grega. Indicadores Econômicos FEE (Online), v. 43, p. 27-44, 2016.

EICHENGREEN, B. From Great Depression to Great Credit Crisis: Similarities, Differences and Lessons. Presented at the 50th Economic Policy Panel Meeting, held in Tilburg on October 23-24, 2009. Disponível em: <http://www.econ.berkeley.edu/ eichengr/great_dep_great_cred_11-09.pdf>. Acesso em: 01 set. 2017.

EUROPEAN CENTRAL BANK. Disponível em: <http://www.ecb.int>. Acesso em: 17 jan. 2009.

FIORI, J. L. Os economistas e a crise. Valor Econômico, São Paulo, p. 9, 25 fev. 2009

FISHER, I. The Debit-deflation theory of great depressions. In: FISHER, Irving. The debt-deflation theory of great depressions. Econometrica: Journal of the Econometric Society, p. 337-357, 1933. 
FRASER, N. Mercantilização, proteção social e emancipação: as ambivalências do feminismo na crise do capitalismo. Revista Direito GV, v. 7, n. 2, p. 617-634, 2011.

GRAZZIOTIN, Henrique de Abreu; HERRLEIN JUNIOR, Ronaldo; AVILA, Róber Iturriet. A economia política institucionalista e o desenvolvimento. In: DATHEIN, Ricardo (Org.). Desenvolvimentismo: o conceito, as bases teóricas, as políticas. 1ed. Porto Alegre: editora da UFRGS, 2015, v., p. 113-156.

GROSS, B. On the "Course" to a New Normal. Investment Outlook, September. PIMCO, 2009. Disponível em: <http://www.pimco.com/LeftNav/Featured+Market+Commentary/1O/2009/Gross+Sept +On+the+Course+to+a+New+Normal.htm>. Acesso em: fev. 2010.

GRUPPI, L. O conceito de hegemonia em Gramsci. 2. ed. Rio de Janeiro: Graal, 1978.

JALIFE-RAHME, A. El síndrome Sansón de EEUU y el nuevo orden financiero multipolar. Disponível em: <http://www.socialismo-o-barbarie.org>. Acesso em: 30 nov. 2008.

KATZ, C. Lección acelerada de capitalismo. Disponível em: <http://www.socialismo-o-barbarie.org>. Acesso em: 8 out. 2008.

KREGEL, J. Financial Flows and International Imbalances: the role of catching up by late-industrializing developing countries, February. Working Paper, n. 528. New York: Levy Economics Institute of Bard College, 2008.

KREGEL, J. Is This the Minsky Moment for Reform of Financial Regulation? February. Working Paper, n. 586. New York: Levy Economics Institute of Bard College, 2010.

KRUGMAN, Paul. A crise de 2008 e a economia da depressão. Rio de Janeiro: Editora Campus/Elsevier, 2009. MINSKY, H. P. Stabilizing an unstable economy. New Haven: Yale University Press, 1986.

NABA, R. Geoeconomía mundial: un cambio estratégico. Disponível em: <http://www.socialismo-o-barbarie.org>. Acesso em: 30 nov. 2008.

OSTRY, J. D., GHOSH, A. R., HABERMEIER, K. F., CHAMON, M., QURESHI, M. S., REINHARDT, D. B. S. Capital Inflows: The Role of Controls. Staff Position Note No. 2010/04. Washington, DC: International Monetary Fund, 2010.

PERICHINSKY, L. Crisis Financiera internacional. El lado oscuro de los fundamentos. Entrelíneas de la Política Económica, Buenos Aires, n. 14, p. 3-12. Disponível em: <http://www.socialismo-o-barbarie.org>. Acesso em: 26 dez. 2008.

PIKETTY, Thomas. Capital in the twenty-first century. Londres: The Belknap press of Harvard University press, 2014. 
POLANYI, K. A Grande transformação: as origens da nossa época. Rio de Janeiro: Campus, 2000.

PHILLIPS, K. Boiling Point. Point: Republicans, Democrats, and the decline of Middle-class Prosperity. Nova York: Random House, 1993. In: ARRIGHI, Giovanni. O longo século XX. Dinheiro, poder e as origens de nosso tempo. Rio de Janeiro: UNESP, 1996.

RESENDE, A. P. Sem lugar para festas, Eu \& Fim de Semana. Valor Econômico, São Paulo, p. 4-13, jan. 2009.

ROBERTS, P. C. ¿Una superpotencia hegemónica...dependiente del capital extranjero? Disponível em: <http://www.socialismo-o-barbarie.org>. Acesso em: 30 nov. 2008.

ROSALES, O. Espacios de convergencia y de cooperación regional, LC/L.3201, Febrero. Santiago, Chile CEPAL, 2010. Disponível em: <www.eclac.cl>. Acesso em: 2009.

ROUBINI, N. La decadencia del Imperio Americano. Disponível em: <http://www.socialismo-o-barbarie. org>. Acesso em: 30 nov. 2008.

SPENCE, M. Emerging Financial Markets after the Global Financial Crisis. PIMCO Viewpoints, August. PIMCO, 2009. Disponível em: <http://www.pimco.com/LeftNav/Viewpoints/2009/Emerging+Financial+Markets+Spence+August.htm>. Acesso em: mai. 2010.

STRANGE, S. The retreat of the state: The diffusion of power in the world economy. Cambridge: Cambridge University Press, 1996.

TAVARES, M. C. A retomada da hegemonia norte-americana. In: TAVARES, Maria da Conceição; FIORI, José Luís (Org.). Poder e dinheiro: uma economia política da globalização. Rio de Janeiro: Vozes, 1997, p. $27-53$.

TOLOUI, R. When Capital Flows Uphill: Emerging Markets as Creditors. PIMCO, 2007. Disponível em: <http:// www.pimco.com/LeftNav/Global+Markets/Capital+Perspectives/2007/Capital+Perspectives-+June+2007. htm>. Acesso em: mai. 2017.

UNCTAD. Trade and Development Report 2007. Geneve: UNCTAD, 2007. Disponível em: <www.unctad. org>. Acesso em: mai. 2017.

WALLERSTEIN, I. Impasses e transformações para o século XXI. In: AXT, Gunter; SCHÜLER, Fernando; SILVA, Juremir Machado da (Org.). Fronteiras do Pensamento: Retratos de um mundo complexo. São Leopoldo: UNISINOS, 2008, p. 385-397.

WALLERSTEIN, I. The essential Wallerstein. New York: the New York Prees, 2000.

WRAY, L. R. The Global Financial Crisis and the Shift to Shadow Banking, Frebuary. Working Paper, n. 587. New York: Levy Economics Institute of Bard College, 2010. 